\title{
Comparative Analysis of Motorcyclists' Gaze Behavior in Different Road Environments
}

\author{
PANAGIOTIS LEMONAKIS, ELENI MISOKEFALOU, NIKOLAOS ELIOU \\ Department of Civil Engineering, University of Thessaly \\ Pedion Areos, Volos, GREECE \\ MYROFORA KORONI \\ Department of Civil Engineering, International University of Greece \\ Thessaloniki, GREECE
}

\begin{abstract}
While car drivers consist the vast majority of road users, motorcycle drivers are considered among the most vulnerable ones with significant participation in accidents. The present study investigates the role of elements that permanently exist in the road environment and affect motorcyclist's behavior since their usefulness requires visual contact between them and the rider during a certain period of time. Therefore, on such an occasion the riders do not monitor the road ahead which is considered as a fundamental driving task and hence the visual search and scan is not directed to the frontal view. The main objective of this paper is to identify and evaluate certain aspects of motorcyclists' behavior influenced by exterior factors, such as observation of vertical signage or advertisement signs, by using naturalistic data. Motorcyclist's visual behavior is evaluated via a continuous recording of his gaze, which acts as the main indicator regarding the rider's performance, with the use of special equipment under naturalistic riding conditions. The selection of a naturalistic method permits continuous data recording, producing real-time data. Thus, the results are reliable and valid to the maximum possible extent. This research is based on a medium-scale experimental procedure that took place in three different road sections in Western Greece. A number of 11 motorcyclists participated in the study. The present research may be used as a tool to improve road infrastructure and to identify attitudes that pose a risk to rider's safety aiming to the creation of a safer road environment, which will lead to less fatal and serious accidents.
\end{abstract}

Key-Words: - Distraction; motorcyclists; naturalistic research; road safety; urban; suburban; gaze;

Received: April 24, 2021. Revised: October 10, 2021. Accepted: November 1, 2021. Published: November 22, 2021.

\section{Introduction}

Among the main causes of road accidents, the distraction of drivers' attention from the task of driving is an issue that has been of increasing concern to the scientific community in recent years. This derives not only from road accident statistics, which classify distraction among the leading causes of fatal accidents but also from naturalistic studies that have been conducted in the field [1, 2, 3].

Driver distraction is a phenomenon that is difficult to be studied since it occurs in various forms and duration and it can be caused by a variety of factors. Apart from the different forms of driver distraction - mental, visual, acoustic, and biomechanical - there is a categorization of the factors of influence based on whether they are based at the external environment or at the vehicle interior.

Furthermore, the distraction of divers' attention may be either harmful, helpful or even necessary for the safe execution of the driving task. The positive impact of distraction on driving could be found for example in the information that the driver may gain by looking not only at a road sign but also at a child that appears at the edge of the road. The negative aspect of driver distraction is crucial for road safety as it captures the driver's attention with results in mental workload. The eliminated mental workload resources lead to diminished ability to operate safely not only in case of an unexpected event but also in regular driving.

The main group of road users that has been studied in terms of distraction is the vehicle drivers. This can be explained by the significant participation of this certain group of drivers in road accidents as well as by the fact that this group is the most populous among all. Scientific research has focused on vehicle drivers leaving a big gap of knowledge regarding the effects of distraction on other road users such as motorcyclists [1]. A holistic approach to road safety requires action to be taken 
for all road users and to improve their driving behavior regardless of the means of transport they use. Road safety audit during the last years includes apart from the vehicles' drivers, the motorcycle ones who share the road network with other vehicle users like the car, bus and truck drivers. Furthermore, the improvement of road networks demands to take into consideration all possible causes of accidents. Recently, motorcyclists participate in road safety audits as they are vulnerable road users with significant participation in accidents. In this direction, the question of driver distraction for motorcycle users should be examined.

The present study is an attempt to produce useful conclusions regarding the role of certain elements of the road environment on motorcyclists' distraction to help the research to fill the pre-existing gap regarding driver distraction. In order to achieve that, data from the behavior of the gaze of the motorcyclists have been collected and analyzed giving useful results. Gaze behavior towards specific road elements on the one hand provides valuable insights about the road environment and the compliance of the rider with the traffic regulations while, on the other hand, it demands the sacrifice of a period of time during which the rider does not look at the field of view ahead. Consequently, depending on the travel speed, a certain distance is traveled where the rider is not aware whether the traffic conditions ahead have been changed e.g. sudden braking from the vehicle in front, animals running into the road.

In an attempt to highlight as many factors of influence of motorcyclists' visual distraction of attention as possible, the study focuses both on factors that are necessary for the execution of the driving task such as road signs, but also on objects that are not necessary for the execution of the driving task such as advertisement signs.

For the objectives of the study, a medium-scale experiment was developed, with the participation of 10 different motorcyclists (11 in the urban road) in 3 different road types. An urban road along with a suburban and a semi-urban road environment were selected. The Gaze Intelligence gaze tracker equipment was used in order to collect the necessary data. These data were time intervals that the gaze of the participant was captured by a road element that was not part of the main road structure. The number of gazes on every object of the above was also taking into consideration.

This research is part of a larger research project conducted by the University of Thessaly, Department of Civil Engineering [1], [2]. The authors strongly believe that this type of research may illuminate an aspect of road safety that has hitherto remained obscure thus helping to reduce road accidents. The results of this type of research procedure are very useful as a tool to encourage the adaptation of more precise regulations concerning the road infrastructure, the placement of roadside elements, etc.

\subsection{Theoretical Background}

In the first International Conference on Distracted Driving the scientific community agreed on a definition for distraction according to which: "Distraction involves a diversion of attention from driving because the driver is temporarily focusing on an object, person, task, or event not related to driving, which reduces the driver's awareness, decision-making, and/or performance, leading to an increased risk of corrective actions, near-crashes, or crashes" [4].

Depending on the mechanism that is activated, distraction of attention may appear in four forms visual, cognitive, biomechanical, and auditory [5]. Depending on their position, distraction potential factors are characterized as internal and external. Internal are those objects that are placed inside the vehicle such as part of the equipment of the vehicle, e.g. the cd player or the speedometer, or objects unrelated to the task of driving such as a mobile phone. On the other hand, external factors are based outside of the vehicle and can be into four categories: built roadway, situational entities, natural environment, and built [6]. The last one includes, apart from the road signs, the advertising signs as well, which may act as attention distractors, interrupting the safe execution of a demanding driving task. Certain circumstances such as increased vehicle speeds and difficult weather conditions may contribute to the composition of a driving task that may lead to a serious road accident.

Various theories have been used in order to analyze the procedure behind the distraction of attention. Regardless of the form, the impact of distraction on drivers is very important. In order for the distracted attention to be applied, a certain amount of mental workload load is used for this purpose, which may be necessary for the safe execution of the driving task. Combining the above with the continuous development of technology and the ever-increasing use of innovative products that require the attention of the user or the recipient of the message they convey, the scientific community is called upon to investigate a particularly demanding issue.

The focus of the researchers' attention on advertising derives from the fact that an advertising 
sign serves its purpose when it is not only seen but also noticed. Advertising signs transmit their message capturing visual attention while the mental workload is also occupied with the analysis of the message transmitted. Especially for advertising signs with changeable messages the period of time needed for this procedure may be long enough to permit a road accident to take place [7]. Taking into consideration the above as well as the fact that any object on the road that does not contribute positively in the task of driving may act as a potential obstacle, many authorities all over the world have established rules and guidelines regarding the placement and the design of the roadside advertisement. At the same time, the industry of advertising manages to maintain the presence the advertising on the road active [8].

\subsection{Frequency of Driver Distraction}

The importance of the issue is highlighted, among others, by the study of both domestic and international road safety statistics which highlight the leading role of driver distraction in road traffic accidents. According to "100 - Car Naturalistic Driving Study" [9] that Virginia Tech Transportation Institute (VTTI) carried out on behalf of NHTSA, driver involvement in secondary tasks is the cause of over $22 \%$ of all crashes and near-crashes [10]. Secondary tasks may include a variety of things such as viewing the scenery, notetaking, reading billboards, etc [4]. External sources of distraction are responsible for $10 \%$ of the accidents [11]. In their study Young et al. [12] claim that more accidents take place in the presence of billboards. Relevant research shows that roadside advertisements attract driver's gaze while fixations upon advertisements can be made at short headways or in other unsafe circumstances [3], [13].

The statistics in Greece lead to similar assumptions. Driver distractions are the cause for $6 \%$ of the fatal road accidents while accidents from an unknown cause are the $18.5 \%$ may also be related to distraction. Furthermore, distraction is the cause of $37.9 \%$ of motorcyclists' fatal accidents [14].

\section{Methodology}

The effects of distraction on human behavior can be evaluated via certain indicators. The most reliable among them is considered to be the time dedicated to gazing at any object under research. Other effects of distracted attention might be loss of control, speed changes, exit from the lane lines, crashes, etc., but the direct connection of distraction with those effects can only be proved with the contribution of the analysis of the gaze behavior.

In a comparative analysis among the methods that are available for such researches, University of Thessaly examined the following categories [15]:

- Studies based on elements of accidents.

- Experimental studies (simulator studies or studies in a test tracks).

- Observational-naturalistic studies (observation of determined point or use of special equipment vehicles).

- Questionnaires studies.

- Specific methods like Peripheral Detection Task and Visual Occlusion.

The conclusions showed that naturalistic methods serve the research most reliably and validly. Naturalistic studies take place in realistic driving conditions, with minimum engagement from the researcher. The results are based on a real-time recording of the gaze direction.

The experiments took place in 3 different road environments i.e., an urban, semiurban, and suburban road segment which length was approximately $4.4 \mathrm{~km}, 2.0 \mathrm{~km}$, and $37.2 \mathrm{~km}$ respectively scheduled in the said chronological order. 11 motorcycle riders were recruited to ride in the urban route with a medium-capacity motorcycle. Since the $11^{\text {th }}$ rider declared that he no longer wished to participated in the measurements due to health reasons only the remaining 10 riders took part in the other two routes. The participants wore special gaze recording equipment throughout the experiments which captured their gaze behavior and saved the results in an mpg video file. Therefore, footage corresponding to each one of the 33 measurements $(1$ route X 11 riders +2 routes X 10 riders $=31$ video files) was obtained after each measurement. In a later stage, these footages were properly processed aiming to identify the duration and sources of riders' distraction. Figure 1 depicts the gaze recording equipment that was used in the experiments together with a random snapshot from the generated footage.

All measurements were executed under good weather conditions although the natural light was often unstable which affected the quality and reliability of the recordings. To overcome this issue special filters were used which balanced the quantity of light that was reaching the lens of the equipment. 

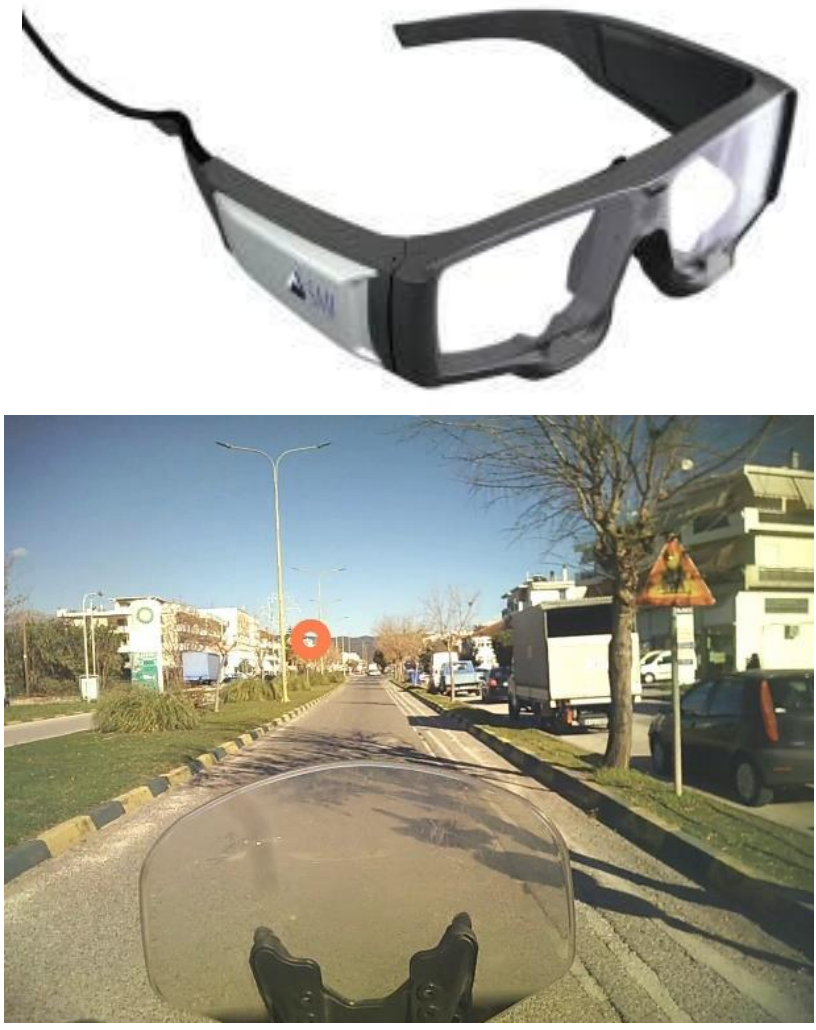

Fig. 1: Recording equipment and random footage's snapshot

\section{Analysis and Results}

A research study based on observing phenomena serves the goal of the production of reliable and valid conclusions. The present research tries to highlight possible interactions that might harm road safety, by analyzing motorcyclists' visual behavior in road network. To this end, descriptive analysis is a very useful tool to identify trends and basic characteristics. For the data analysis, a total of 1625 cases have been used (804 from urban road environment, 678 for suburban road environment, and 143 for semi-urban environment). A total of 10 (11 in case of urban environment) motorcyclists participated in the measurements. Distraction time intervals were classified into four groups: $0-0.7$ seconds, 0.71 - 1.6 seconds, $1.61-2.0$ seconds and anything more than 2 seconds [3]. The study focuses on driving distraction caused by specific visual stimuli for unsafe time intervals, greater than 0.7 seconds as this is considered to be the threshold for safe reaction times.

\subsection{Analysis of Significant Distractions of Attention Per Rider}

The first crucial step is to detect the number of cases that each rider was distracted from the task of driving for time intervals greater than $0.7 \mathrm{sec}, 1.6$ $\mathrm{sec}$, and $2 \mathrm{sec}$ respectively. For this purpose, each road environment is separately analyzed. The fact that the duration of each measurement differs leads to the use of an indicator that allows the objective comparison of the data. This indicator appears as the number of distractions per minute of driving and it is presented in Figure 2. As it might be expected, the urban environment contains much more distraction cases than the other two road environments. This is not a surprise because, by nature, urban environments contain more sources of distraction than others.
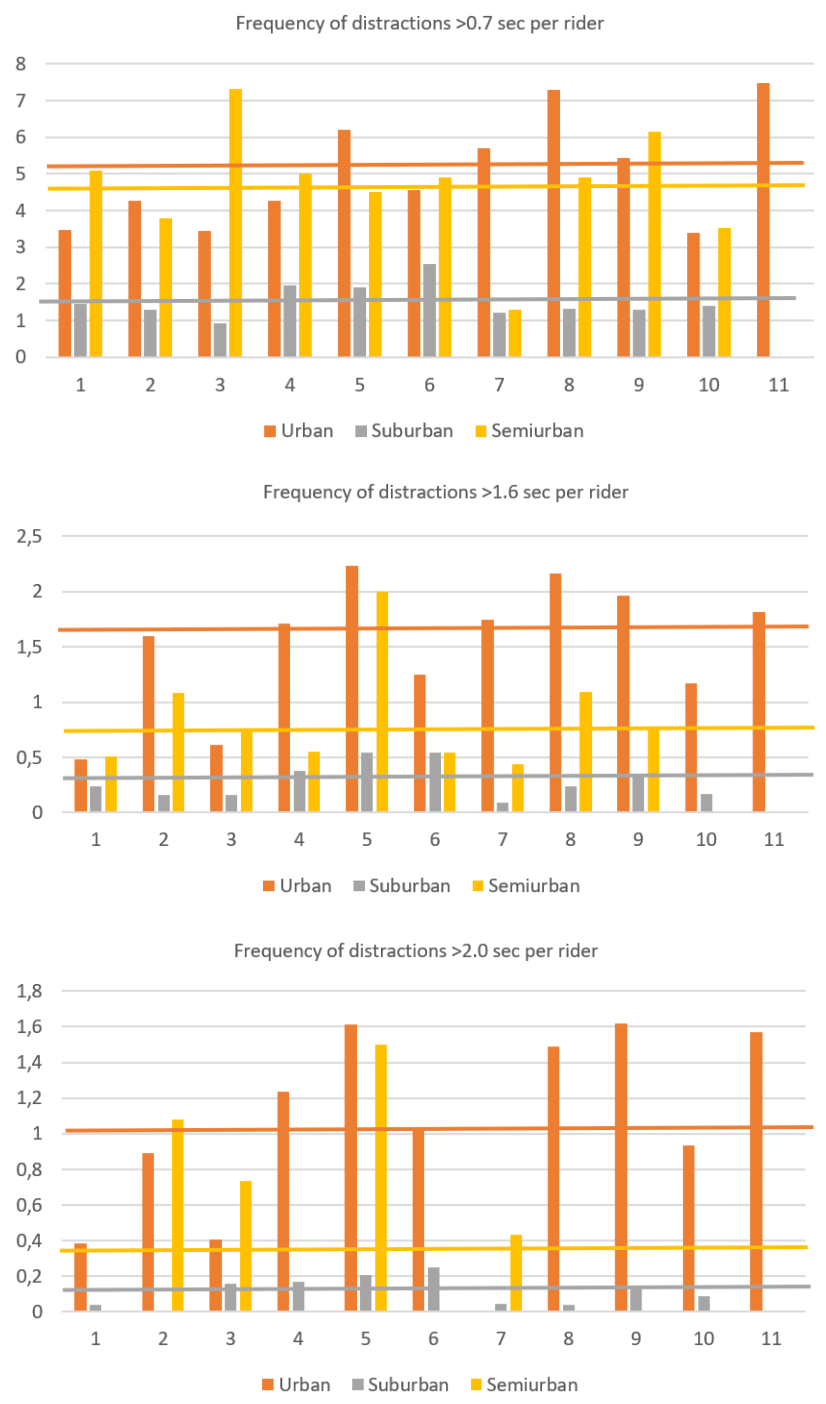

Fig. 2: Frequency of distractions per rider in Urban, Suburban and Semi-urban road environment

The study of the average distraction time per rider shows that while urban routes have higher 
results, the second place alternates between the suburban and the urban route. The diagrams in Figure 3 show that some drivers have greater average times at the urban route and others at the semi-urban route. The higher indicators of urban routes find an explanation in the fact that within the city the speeds are lower therefore each source of distraction is visible for a longer period of time. It is worth noting that, despite the relatively reduced speeds, the majority of the riders were not distracted for more than 2 seconds on the semi-urban route.
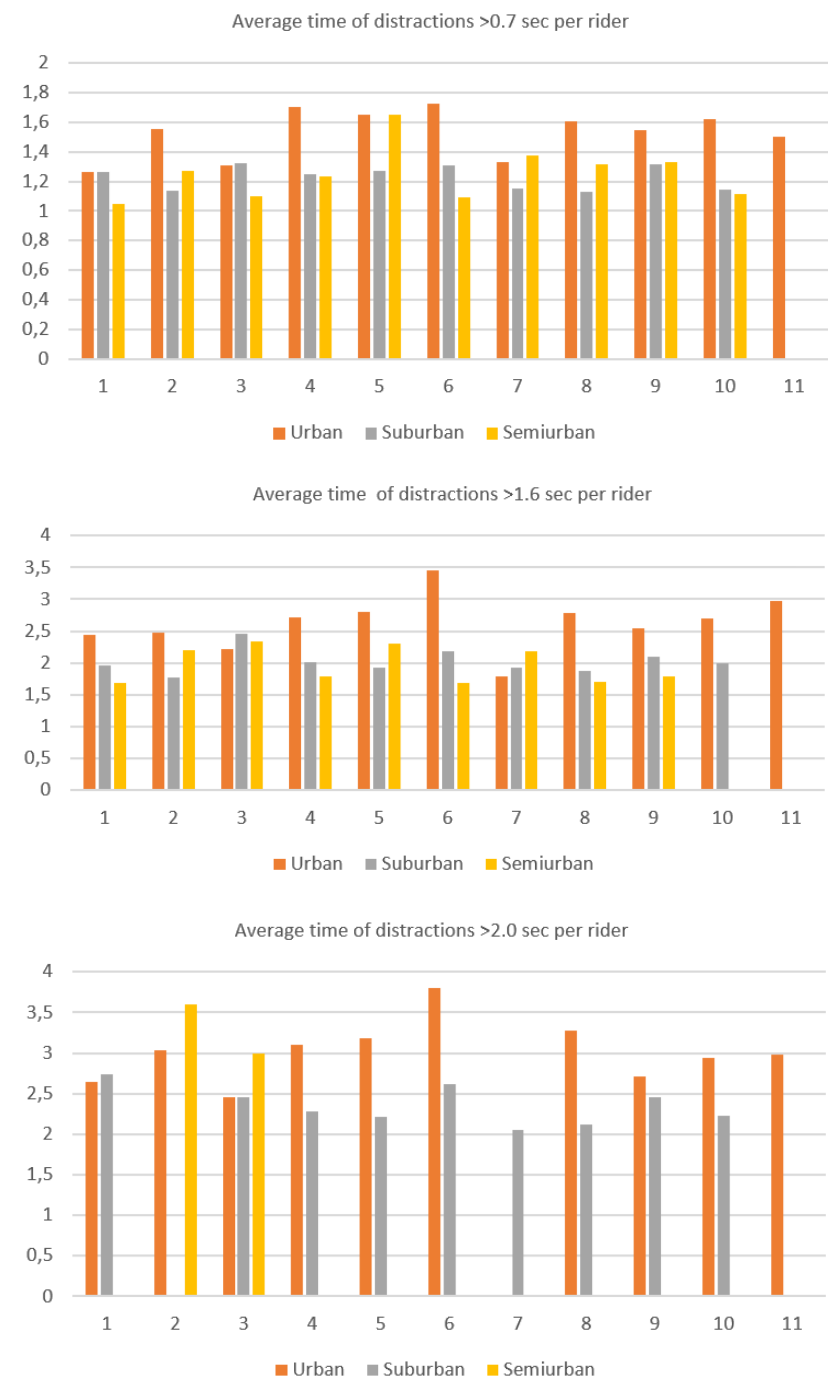

Fig. 3: Average time of distractions per rider in Urban, Suburban and Semi-urban road environment

\subsection{Analysis of Significant Distractions of Attention Per Road Element}

Road elements belong into 5 categories. The first category consists of road signs, the second category consists of advertising signs, the third category consists of distraction points whereas road signs and advertising signs exist and both attract rider's attention, the fourth category consists of the variable message signs which at the present study can be found only in the urban environment and all the other entities like gas stations consist the fifth category. At this point it should be noted that, with respect to the comparability of the data the frequency is presented as the number of distraction per minute of the average time of driving at each route. The frequency of distraction regarding every category of the above mentioned shows the superiority of advertising in every road environment (Figure 4).

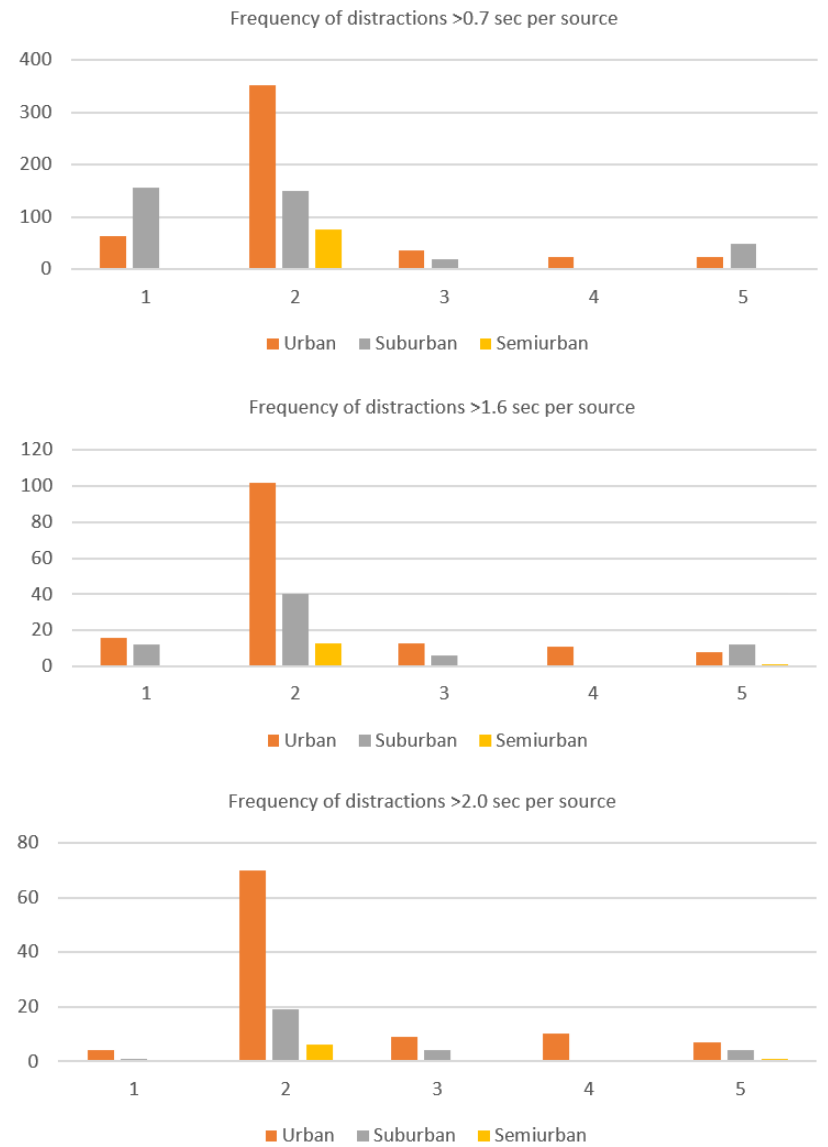

Fig. 4: Frequency of distractions per source of distraction in Urban, Suburban and Semi-urban road environment

Focusing on the average time spent on each element per route (Figure 5), in general, semi-urban route concentrates lower average time intervals at all element categories than the other two. Other than that, the urban environment gives the highest average times for all elements. Variable message signs concentrate the higher prices but there are no available data for the suburban and the semi-urban environment. Advertising and other entities have slightly increased presence compared to road signs on all routes.

Except for the unrelated to the driving task elements, these results include road signs which are necessary to be seen. Especially for road signs 
(category 1), they do not distract drivers at the semiurban route for time intervals higher than $1.6 \mathrm{sec}$.
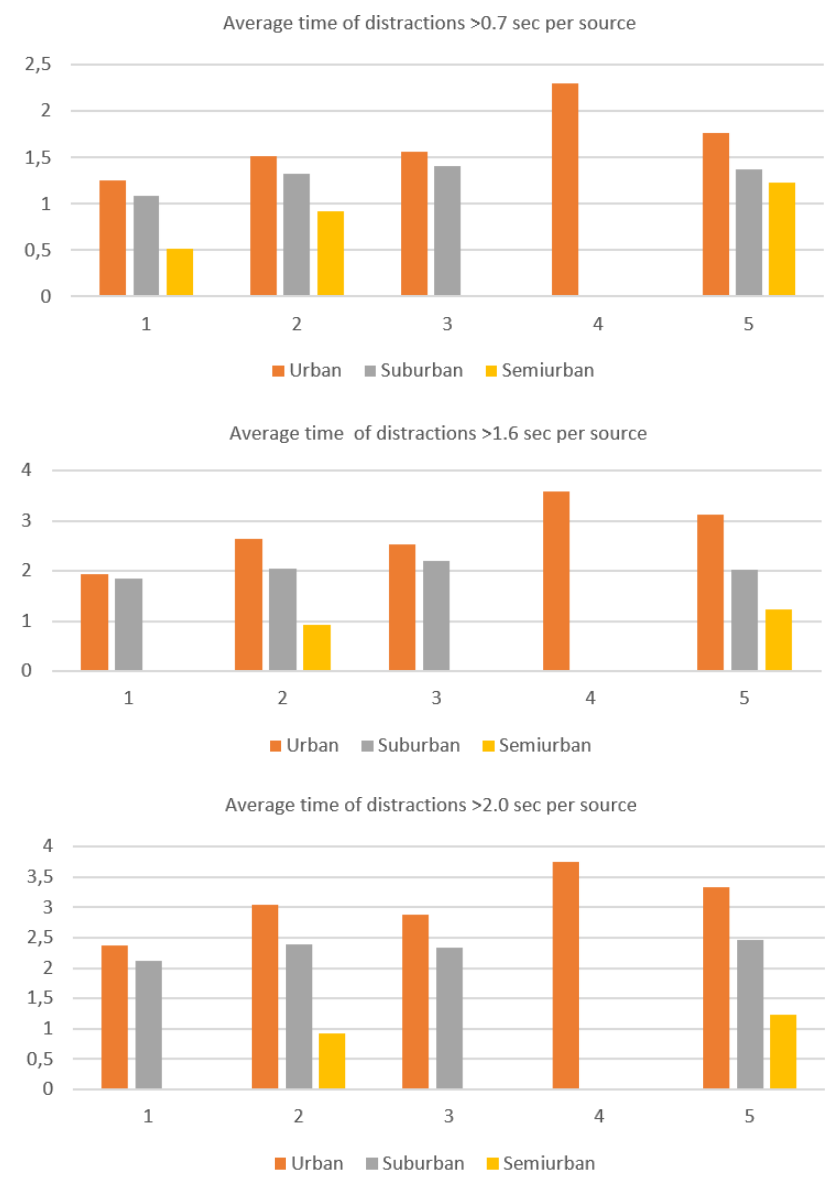

Fig. 5: Average distraction time per element category in Urban, Suburban, and Semi-urban road environment

\subsection{Analysis of Significant Distractions of Attention Per Number of Road Element}

Research has shown that the number of elements that may distract riders' attention plays a significant role at the average time of distraction [2]. The present study confirms the above findings for all three-time milestones only on the urban route. As shown in the charts (Figure 6) for suburban and semi-urban routes the results do not vary wildly.

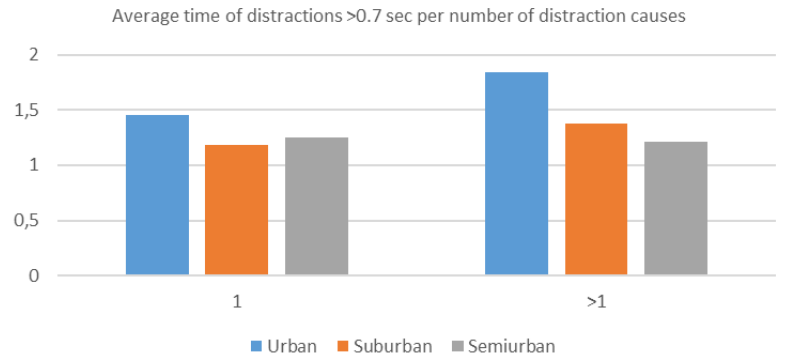

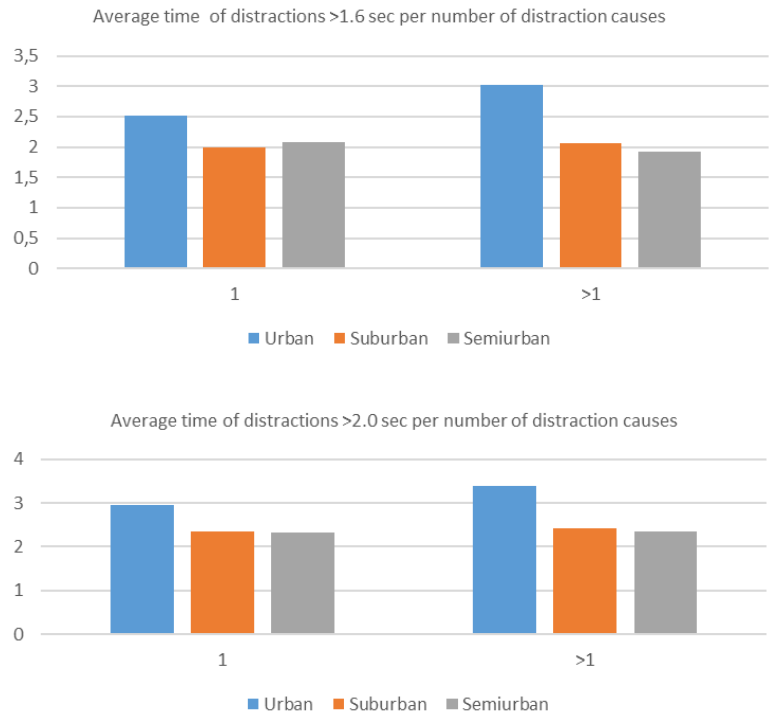

Fig. 6: Average distraction time per number of elements in Urban, Suburban and Semi-urban road environment

\subsection{Analysis of Advertising Related Distractions}

Focusing on advertising, the findings in Table 1 show that even though urban environments are characterized by longer distractions from billboards all three road environments host objects which, while offering absolutely nothing to the task of driving, reduce significantly the time devoted to it, endangering not only the driver but also other road users.

Table 1 shows the average time as well as the number of glances on billboards. It can be seen that in urban road environment the distraction for more than 2 seconds occurs in many cases and its average duration exceeds 3 seconds, a fact that is very dangerous for the safety of road users, among whom are many pedestrians.

Table 1. Frequency and average time of advertising related distractions

\begin{tabular}{cccc}
\hline \hline \multicolumn{4}{c}{ Urban } \\
\hline & $\begin{array}{c}\text { Distraction } \\
>0.7 \mathrm{~s}\end{array}$ & $\begin{array}{c}\text { Distraction } \\
>1.6 \mathrm{~s}\end{array}$ & $\begin{array}{c}\text { Distraction } \\
>2 \mathrm{~s}\end{array}$ \\
\hline Frequency & 429 & 130 & 95 \\
\hline Average & 1,5772 & 2,7348 & 3,1193 \\
\hline \hline \multicolumn{4}{c}{ Suburban } \\
\hline & $\begin{array}{c}\text { Distraction } \\
>0.7 \mathrm{~s}\end{array}$ & $\begin{array}{c}\text { Distraction } \\
>1.6 \mathrm{~s}\end{array}$ & $\begin{array}{c}\text { Distraction } \\
>2 \mathrm{~s}\end{array}$ \\
\hline Frequency & 219 & 58 & 27 \\
\hline Average & 1,3447 & 2,0653 & 2,398 \\
\hline \multicolumn{4}{c}{ Semi-urban } \\
\hline Distraction & Distraction & Distraction \\
& $>0.7 \mathrm{~s}$ & $>1.6 \mathrm{~s}$ & $>2 \mathrm{~s}$ \\
\hline Frequency & 79 & 14 & 7 \\
\hline
\end{tabular}




\begin{tabular}{llll}
\hline Average & 1,2444 & 2,0319 & 2,3194 \\
\hline \hline
\end{tabular}

Figure 7 presents the average distraction time from advertising signs for each rider respectively. The analysis highlights the critical role of advertising in road safety as well as the different driving behavior among the riders. It is worth noting that none of them record values less than 0.7 seconds. The fact that every driver has such high average distractions across all road networks raises concerns about the safety of these roads.
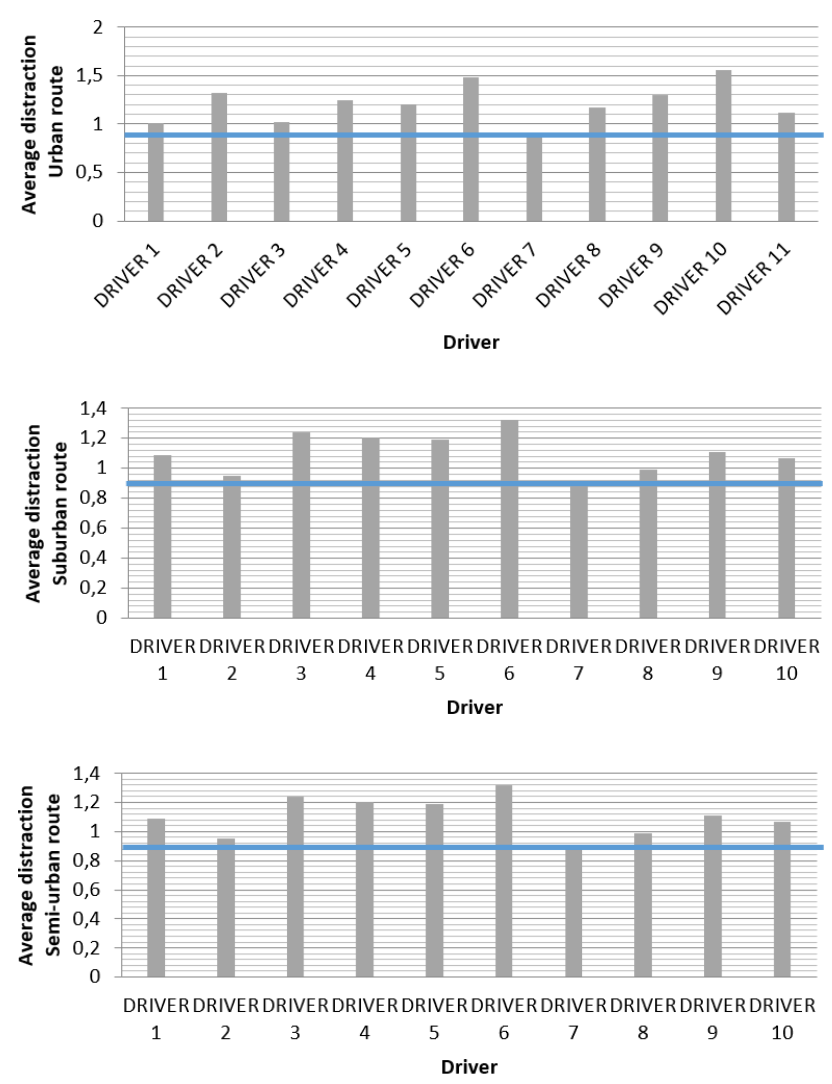

Fig. 7: Average time of advertising related distractions per rider in Urban, Suburban, and Semiurban road environment

\section{Conclusion}

The distraction of drivers is a matter of paramount importance for road safety. This issue threatens the lives and safety of the drivers themselves and other road users. Motorcyclists are a significant part of road users and the fact that their involvement in fatal accidents is high and that they are particularly vulnerable road users leads the research on the subject to target them as well.

The research aims to quantify the effect of motorcyclists' attention while identifying the causes that cause it and are based on the road environment. These elements that exist in the motorcyclist's field of vision threaten the safe execution of driving, consuming mental workload resources that are necessary for the proper processing of information useful for the work of driving. Among these elements the analysis of the effect of advertisement, the role of which is to distract the driver in order to convey the message it contains is of paramount importance.

Naturalistic methods offer the opportunity of real-time data produced by continuous data recording with a result in reliability and validity. Among the restrictions of the research, it is important to mention the lack of demographics that do not allow the performance of an inductive approach, the inability to create different driving scenarios as well as control environmental conditions.

The study of the frequency of distraction cases shows that numerous road elements at the route attract driver's attention from the driving task for unsafe - in terms of road safety - time intervals. Obviously, there is a positive correlation between the number of sources and the number of actual distractions that may be harmful to road safety. This explains the fact that urban environments appear to have the highest number of distraction cases than the other two.

Average distraction times differ among drivers but every one of them is being distracted for unsafe periods - more than $1 \mathrm{sec}$ at all three road environments. Riders may feel safer to be distracted for longer time intervals in urban environments. This is probably directly related to the lower speeds developed on these routes.

The fact that more than one element existing at the place distract the driver's attention for significantly longer periods raises concerns regarding the proximity of the elements.

Besides the concern that arises from the dominant role of advertising, another crucial issue emerges from the analysis of the frequency of distraction respectively for each road element category. Numerous road signs at the route attract rider's attention from the driving task for unsafe - in terms of road safety - time intervals. On the one hand, road signs have to be seen and noticed but on the other hand, the question arises regarding the exact position of the road signs and the necessity of a more careful approach regarding their placement on the roadside.

Focusing on the elements that are not necessary for the execution of the driving task urban road environment might be more dangerous in terms of road safety than the suburban or the semi-urban. Advertising-related elements and others unrelated to 
the driving task elements on the road attract driver's attention for time intervals greater than the ones that derive from driving-related elements. The fact that the average distraction times caused by non-related to the driving task elements varies among the drivers reveals the need for a more precise analysis which might take into consideration the personal characteristics of each driver. A more precise analysis must take into consideration the speeds in order to conclude properly.

Adverting related legislation exists but, in many cases, remains inapplicable. More work has to be made in that direction in order to prevent future accidents. To this end collaboration with experts and determination of the accident risk is deemed necessary. The present research may be used as a tool to improve road infrastructure and to eliminate road visual pollution aiming to the creation of a safer road environment, which will lead to fewer fatal and serious accidents.

\section{References:}

[1] Lemonakis. P., Koroni M., Misokefalou. E., Eliou. N. "Recording and evaluation of motorcyclists' distraction of attention in urban areas", 5th Conference on Sustainable Urban Mobility - CSUM2020, 17-19 June 2020, Online Conference

[2] Lemonakis. P., Misokefalou. E., Koroni M., Eliou. N. "Recording and evaluating motorcyclists' gaze behaviour in rural roads", 13th International Motorcycle Conference, 1/96/10/2020, Online Conference

[3] Misokefalou, E.: Investigation into and modeling of factors influencing drivers' attention and impacts on road safety. Ph.D. Thesis, University of Thessaly, Volos, Greece (2014).

[4] Hedlund, J., Simpson, H. M. \& Mayhew, D. R., 2006. International Conference on Distracted Driving - Summary of Proceedings and Recommendations. Toronto, International Conference on Distracted Driving.

[5] Ranney, T.A., Garrott, W.R. \& Goodman, M.J.: National Highway Traffic Safety Administration driver distraction research: past, present and future. Paper presented at the 17th International Technical Conference on Enhanced Safety of Vehicles, Amsterdam (2001).

[6] Horberry, T. \& Edquist, J.: Distractions Outside The Vehicle. $\Sigma \tau$ o: Driver Distraction: Theory, Effects and Mitigation (Chapter 13). Florida: CRC Press, pp. 215-228 (2008).
[7] Oviedo-Trespalacios, O., Truelove, V., Watson, B. \& Hilton, J. A.: The impact of road advertising on driver behavior and implications for road safety: A critical systematic review. Transportation Research Part A, 122, pp. 85-98 (2019).

[8] Herrstedt, L., Greibe, P. \& Andersson, P.: Roadside Advertising Affects Driver Attention and Road Safety. 3rd International Conference on Driver Distraction and Inattention, September 4-6, 2013, Gothenburg, Sweden (2013).

[9] Klauer, S.G., Dingus, T.A., Neale, V.L., Sudweeks, J.D., Ramsey, D.J.: The impact of driver inattention on near-crash/crash risk: an analysis using the 100-car naturalistic driving study data. Report No. DOT HS 810 594, National Highway Traffic Safety Administration, Washington, D.C (2006).

[10] NHTSA's National Center for Statistics and Analysis.: An examination of driver distraction as recorded in NHTSA databases, Research note. Report No. DOT HS 811 216, National Highway Traffic Safety Administration, Washington, D.C. (2009).

[11] Wallace, B.: Driver distraction by advertising: Genuine risk or urban myth? Municipal Engineer, 156, pp. 185-190 (2003).

[12] Young, K., Mahfoud, J.M., Stanton, N. A., Salmon, P.M., Jenkins, D.P., Walker, G.H.: Conflicts of interest: The implications of roadside advertising for driver attention while driving: Skill and awareness during inspection of the scene. Transportation Research Part F 12, pp. 381-388 (2009).

[13] Smiley, A., Smahel, T., Eizenman, M. 2004. Impact of video advertising on driver fixation patterns. Transport Research Record, 1899, 76-83.

[14] Greek Police, http://www. astynomia.gr, last accessed 2020/3/26.

[15] Misokefalou, E., Eliou, N.: Comparative analysis of drivers' distraction assessment methods. Paper presented at the 22nd ICTCT Workshop, Towards and Beyond the 2010 Road Safety Targets-Identifying the Stubborn Issues and their Solutions, Leeds, UK (2009).

\section{Contribution of Individual Authors to the Creation of a Scientific Article (Ghostwriting Policy)}

The authors confirm contribution to the paper as follows: study conception and design: $P$. Lemonakis, E. Misokefalou, and M. Koroni; 
analysis and interpretation of results: P. Lemonakis, E. Misokefalou, M. Koroni and N. Eliou; draft manuscript preparation: P. Lemonakis, E. Misokefalou, M. Koroni. All authors reviewed the results and approved the final version of the manuscript.

\section{Sources of Funding for Research Presented} in a Scientific Article or Scientific Article Itself This research study was conducted under the post-doc scholarship supported by the University of Thessaly and exclusively funded by Stavros Niarchos Foundation.

I IN/SNF $\begin{aligned} & \text { IAPYMA ETAYPOE NIAPXOE } \\ & \text { STAVROS NIARCHOS FOUNDATION }\end{aligned}$

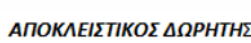

Creative Commons Attribution License 4.0 (Attribution 4.0 International, CC BY 4.0)

This article is published under the terms of the Creative Commons Attribution License 4.0 https://creativecommons.org/licenses/by/4.0/deed.en US 